\title{
lon-exchange extraction of organic acids in water samples. Study of the influential factors and interactions
}

\author{
V. Desauziers ${ }^{1, *}$, C. Boucharat ${ }^{1}$ and P. Le Cloirec ${ }^{2}$ \\ ${ }^{1}$ Laboratoire Génie de l'Environnement Industriel, École des Mines d'Alès, \\ 6 avenue de Clavières, 30319 Alès Cedex, France \\ ${ }^{2}$ École des Mines de Nantes, D.S.E.E, 4 rue Alfred Kastler, BP. 20722, 44307 Nantes, Cedex 03, France
}

\begin{abstract}
The objective is to concentrate organic acid traces in water samples. The influence of several parameters and their interactions on the adsorption of organic acids on anion exchange resins was studied. A complete factorial design $2^{4}$ was hence performed. The measured response corresponds to the maximal percolation volume and the studied parameters were the nature and the mass of the resin, the percolation flow-rate and the ionic strength of the analysed water. The results shown that the percolation flow-rate is significant but not really important compared to the resin mass and to the nature of water. Indeed, the sample inorganic anions can compete with organic acids. This adsorption competition appears to be more important when a macroporous resin is used. A "gel-type" resin could be therefore better adapted to the extraction of organic acids in water samples.
\end{abstract}

Key words. Organic acids - water analysis - ion exchange resin - adsorption - experimental design.

\section{Introduction}

Carboxylic acids represent around $30 \%$ of the organic matter identified in natural waters [1-3]. These compounds have mainly a natural origin (fatty acids) [4]. However, some other compounds believing to this fraction may be present at trace level (massic fraction lower than 1\%) and may be toxic.

Organic acids may also be formed by the degradation of the organic matter during drinking water treatment and can constitute the main final oxydation by-products $[2,5,6]$.

The fate and toxicity of some of these compounds have led to establish a normalization procedure. So, some classes of organic acids are particularly studied such as phe- noxyalkanoic acids (acidic herbicides) which can be found in various surface waters and haloacetic acids, which are the main chloration by-products.

The european regulation limits to $100 \mathrm{ng} \mathrm{L}^{-1}$ the individual concentrations of the acidic herbicides in drinking water (Directive 76/464 EEC of the Council). It is therefore necessary to apply specific and sensitive analytical methods. These methods generally involve an extraction/preconcentration step followed by a chromatographic analysis.

Among the preconcentration methods, liquid/liquid extraction is often used. An in situ derivatization can be previously carried out to lower the polarity of the analytes [7-9]. Ion-pairing can be also performed [10]. These proce-

* Correspondence and reprints.

Received February 25, 1998; revised May 13, 1998; accepted May 20, 1998. 


\section{Original articles}

dures are however not easy to perform, are solvent-consumming and the enrichment step generally requires a supplementary solvent evaporation.

Solid-phase extraction was developped more recently and appears to be better adapted to the organic acid extraction because of the wide diversity of the different phases. Amongst the main phases used, it is possible to distinguish apolar sorbents such as bonded silica $\mathrm{C}_{18}$ [11], polymeric resins (styrene divinylbenzene polymer) $[12,13]$ or graphitized carbon $[14,15]$. These sorbents are not specific and permit the extraction of a wide scale of organic compounds. The extraction of carboxylic acids by using these sorbents consequently requires the acidification of the percolated sample in order to improve their retention by hydrophobic interactions.

A specific extraction of organic acids can be carried out by using an anion-exchange sorbent. The support is generally polymeric (styrene divinylbenzene) or based on a microporous silica bonded with quaternary ammonium groups in the case of strong anion exchange [16,17]. The sorbents based on a silica support have however a lower exchange capacity than the polymeric phases. They can be used only in the $\mathrm{pH}$ range 2-8. In this study, we consequently chose to use polymeric sorbents.

According to the literature [12,13,18-21], the results obtained by using anion-exchange resins (percolated volume, concentration factor, recovery yields: $90-100 \%$ ) are comparable to those obtained with non-specific sorbents. So, ion-exchange resin extraction would not be affected by interfering compounds from the organic or mineral matrices. However, other authors have stated a decreasing of the extraction yield during the acidic herbicide preconcentration on an anion-exchange resin, on the contrary of an extraction on graphitized carbon [14].

One of the objectives of this study was to check the influence of the sample ionic strength on the retention of organic acids preconcentrated on an anion exchange resin. Two resins, with different macromolecular networks (macroand microreticular) were also tested. Indeed, the ion diffusion rate can be different according to these two structures. Moreover, the mass of resin introduced in the preconcentration column and the percolation flow-rate were studied. It was shown that, considering porous material, the flow-rate may considerably influence the adsorption kinetic [22]. In order to estimate the signification of these parameters and interactions, a two-level complete factorial design $\left(2^{4}\right)$ was performed. The influence of the different factors was evaluated on the maximum sample volume which can be percolated through the resin. This volume corresponds to the breakthrough volume of the less retained compounds.

\section{Material and methods}

\section{Reagents}

Stock solutions $\left(1 \mathrm{~g} \mathrm{~L}^{-1}\right)$ of all the studied acids were prepared in methanol (Carlo Erba RS for HPLC, 99.9\%).

Studied model compounds: acetic acid (Merck Suprapur 96\%), butyric acid (Prolabo Rectapur 99\%), dichloroacetic acid (Aldrich +99\%), benzoic acid (Riedel de Haën 99.9\%), 4-chlorobenzoic acid (Merck +98\%), 2,4-D (2,4dichlorophenoxyacetic acid) (Altech 99\%).

Working solutions were prepared by dilution in pure water (MilliQ, Millipore) of the stock solutions.

\section{Chromatographic material}

\section{lon-exchange chromatography}

An isocratic pump (Waters 510), equipped with a Rheodyne injection valve (injected volume: $100 \mu \mathrm{L}$ ) and with a Waters IC-Pak Anion HR column $(4.6 \times 75 \mathrm{~mm})$ filled with a polymeric resin bonded with quaternary ammonium groups (particle diameter: $5 \mu \mathrm{m}$ ) was used. The mobile phase contained boric acid $\left(0.27 \mathrm{~g} \mathrm{~L}^{-1}-\right.$ Aldrich), sodium tetraborate $(0.75$ $\mathrm{g} \mathrm{L}^{-1}-$ Aldrich), acetonitrile 6\% (v/v) (Carlo Erba RS for HPLC, $99.8 \%$ ). The flow-rate was $1 \mathrm{~mL} \mathrm{~min}^{-1}$. Direct UV detection was performed at $215 \mathrm{~nm}$ (Varian 2050). Chromatograms were recorded with a Shimadzu C-R5A integrator.

\section{Ion-exclusion chromatography}

The same material than described above was used. The column was a Supelcogel C-610H $(30 \mathrm{~cm} \times 7.8 \mathrm{~mm})$ (Supelco), filled with a sulfonated styrene divinylbenzene polymer (particle diameter: $5 \mu \mathrm{m}$ ). The mobile phase was composed of $0.1 \%$ (v/v) phosphoric acid (Carlo Erba 85\%)

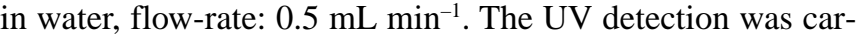
ried out at $210 \mathrm{~nm}$.

\section{Analysis of inorganic anions by capillary electrophoresis}

A Quanta 4000 capillary electrophoresis (Waters), equipped with a Millenium 2010 (Waters) software was used, with a fused silica capillary $(60 \mathrm{~cm} \times 75 \mu \mathrm{m})$. The electrolyte was an aqueous solution of sodium chromate $0.1 \mathrm{~mol} \mathrm{~L}^{-1}$ (Aldrich, 99\%), containing an electroosmotic flow modifier OFM $0.5 \times 10^{-3} \mathrm{~mol} \mathrm{~L}^{-1}$ (Waters). An indirect UV detection was carried out at $254 \mathrm{~nm}$.

\section{Determination of the dissolved organic carbon (DOC):}

A TOC analyser, TOC-5000 (Shimadzu) was used.

\section{Extraction material and column preparation}

The solid-phase extraction was performed by percolating the sample through the preconcentration column by using an electromagnetic pump (Prominent). The column used was a glass low/medium pressure column (Supelco) $(0.9 \mathrm{~cm} \times$ $20 \mathrm{~cm}$ ). Tubes and connections were Teflon-made.

The characteristics of the resins used are summarized in table I. The total exchange capacity of both resins was $3.8 \mathrm{meq} \mathrm{g}^{-1}$ and the $\mathrm{pH}$ range of use was $0-14$.

Column preparation: the resin was dry weighted on a glass fritt, then cyclic washes by MilliQ water and methanol were applied, followed by cyclic washes by MilliQ water and $1 \mathrm{~mol} \mathrm{~L}^{-1} \mathrm{HCl}$, in order to eliminate eventual impurities [16]. The resin, suspended in water, was then introduced in the column and was allowed to settle slowly, so that the granulometric repartition was homogeneous. A glass wool stopper, carefully washed, (acetone, methanol and water) 


\section{Original articles}

Table I. Characteristics of the anion-exchange resins used.

\begin{tabular}{|c|c|c|c|c|}
\hline Resin & Type & Support & Bonding & Granulometry \\
\hline $\begin{array}{l}\text { Amberlite IRA-910 } \\
\text { (Fluka) }\end{array}$ & Macroreticular & SDVB polymer & $-\mathrm{N}^{+}\left(\mathrm{R}^{\prime} \mathrm{OH}\right) \mathrm{R}_{2}$ & 0.45 to $0.55 \mathrm{~mm}$ \\
\hline $\begin{array}{l}\text { Amberlite IRA-420 } \\
\text { (Janssen Chimica) }\end{array}$ & Microreticular & SDVB polymer & $-\mathrm{N}^{+} \mathrm{R}_{3}$ & 0.4 to $0.5 \mathrm{~mm}$ \\
\hline
\end{tabular}

was placed above the resin. Then, a water rinse allowed to improve the packing and to reach a neutral $\mathrm{pH}$.

The resin can be stored few weeks without leading it to dryness.

\section{Results and discussion}

In order to check their behaviour during the percolation of the water sample, the model compounds were injected into a HPLC system where the stationary phase was the same as that chosen for the preconcentration step (polymeric resin bonded with quaternary ammonium groups). It would be, hence, relatively easy to determine the less retained compound. Its breakthrough volume would then allow to define the maximal sample volume to be percolated through the ion-exchange resin.

According to the chromatogram (Fig. 1), it appears that the most polar acids (acetic and butyric) were the less retained compounds on the ion-exchange resin. Figure 2 shows that in this case, the retention was not related to the hydrophobic properties of the molecules: no "reversedphase" interactions would therefore occured, or they would be negligible. Moreover, acetonitrile had no influence on their elution (Fig. 3). Consequently, only ion-exchange could be responsible of the retention of these compounds. On the contrary, for the other compounds, a good linearity existed

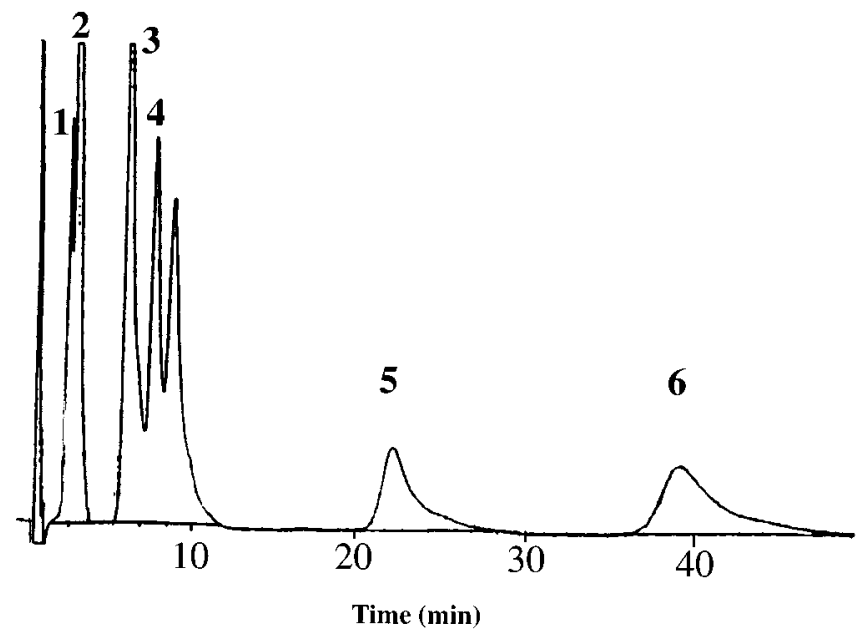

Fig. 1. Analysis of the model compounds on an anion-exchange column. 1. Acetic acid $\left(50 \mathrm{mg} \mathrm{L}^{-1}\right) \mathbf{2}$. Butyric acid $\left(50 \mathrm{mg} \mathrm{L}^{-1}\right) \mathbf{3}$. Dichloroacetic acid $\left(20 \mathrm{mg} \mathrm{L}^{-1}\right)$ 4. Benzoic acid $\left(1 \mathrm{mg} \mathrm{L}^{-1}\right) \mathbf{5}$. 4-chlorobenzoic acid $\left(1 \mathrm{mg} \mathrm{L}^{-1}\right)$ 6. 2,4-D $\left(1 \mathrm{mg} \mathrm{L}^{-1}\right)$. The peak between 4 and 5 corresponds to the benzene sulfonic acid which is not studied here. between hydrophobicity, expressed here by the water/octanol partition coefficient $(\log P)$ [23] and the capacity factor (coefficient of correlation: 0.988) (Fig. 2). The retention could be therefore partially explained by "reversed-phase"

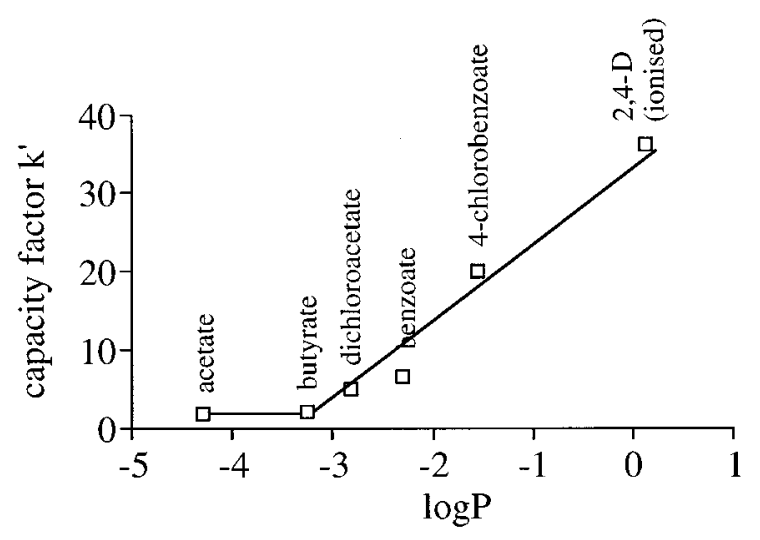

Fig. 2. Relation between the hydrophobicity of the ionised acids and their capacity factors on an anion-exchange column.
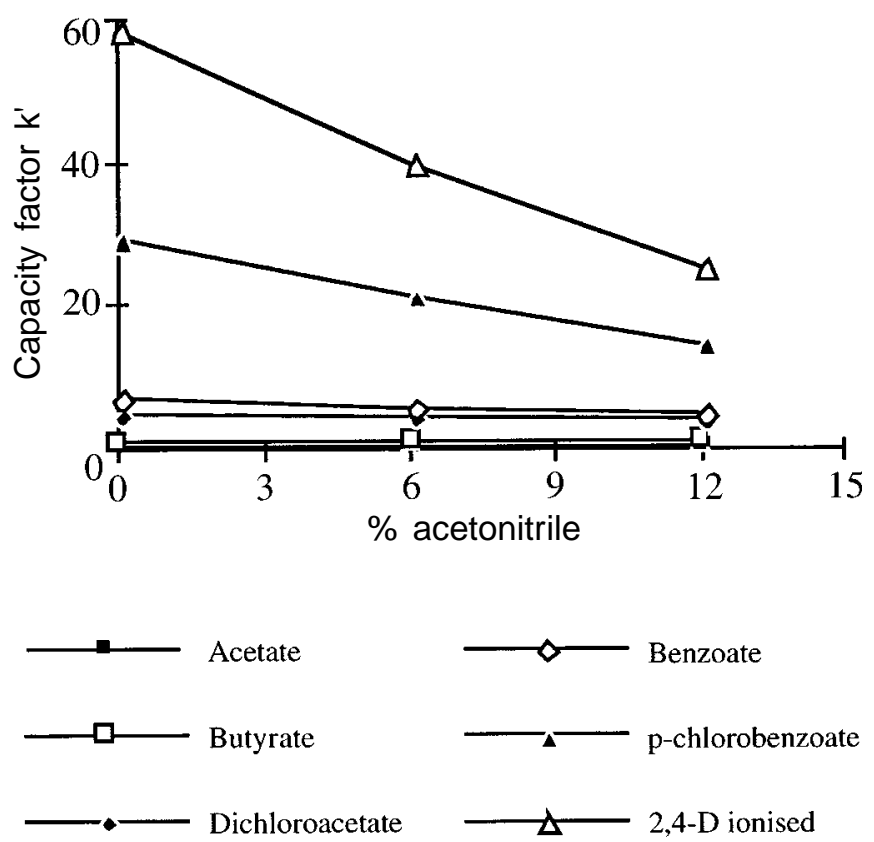

Fig. 3. Influence on the acid retention of the acetonitrile content in the mobile phase. 
interactions between the polymeric support of the phase and the solutes. This was confirmed by the influence of acetonitrile on the acid capacity factors (Fig. 3).

The less retained compound on the studied anionexchange resin is acetic acid. It will, hence, limit the enrichment step by defining the maximum sample volume to be percolated through the resin.

The influence of different parameters (mass of resin, percolation flow-rate, nature of the water and of the ionexchange resin) and their interactions on the breakthrough volume of acetic acid was studied by the experimental design method. A complete $2^{4}$ factorial design was therefore envisaged and has led to define an experimental field including 16 experiments.

The response measured was the breakthrough volume $\left(V_{\mathrm{p}}\right)$ of acetic acid $\left(10 \mathrm{mg} \mathrm{L}^{-1}\right) . V_{\mathrm{p}}$ was determined by plotting the frontal elution curve obtained after the analysis by ionexclusion chromatography of $10 \mathrm{~mL}$ fractions of the percolate.

The choice of the factors and of the levels which limited the experimental field were determined after preliminary experiments. Two levels, (+1) and $(-1)$, were defined for each of the studied factors (Tab. II). The experimental matrix is represented table II, with the corresponding responses.

The effect of a factor $i$ on the measured response is defined as the coefficient $b_{i}$, obtained by comparing the values of the response when the factor varies from -1 to +1 .

The interaction, expressed as the coefficient $b_{i j, n}(n=$ number of factors), is considered when the effect of one of the factors depends on the level of another factor.

The response is expressed as the following polynomial relation (1):

$$
y=b_{0}+\sum_{i} b_{i} X_{\mathrm{i}}+\sum_{i j} b_{i j} X_{i} X_{j}+\ldots
$$

Table III. Effects of the factors and interactions on the breakthrough volume of acetic acid.

\begin{tabular}{lcc}
\hline Factor & $\begin{array}{c}\text { Effects and } \\
\text { interactions }\end{array}$ & Results \\
\hline Mean & $b_{0}$ & 310 \\
Flow-rate & $b_{1}$ & -29 \\
Nature of the water & $b_{2}$ & -228 \\
Nature of the resin & $b_{3}$ & -40 \\
Resin mass & $b_{4}$ & 135 \\
Flow-rate-Nature of the water & $b_{12}$ & 8.7 \\
Nature of the water-Nature & $b_{23}$ & -2.5 \\
of the resin & & \\
Flow-rate-Nature of the resin & $b_{13}$ & 8.7 \\
Flow-rate-Resin mass & $b_{14}$ & 3.7 \\
Nature of the water-Resin mass & $b_{24}$ & -102 \\
Nature of the resin-Resin mass & $b_{34}$ & -28 \\
$\begin{array}{l}\text { Flow-rate-Nature of the water-Nature } \\
\text { of the resin }\end{array}$ & $b_{123}$ & -3.8 \\
$\begin{array}{l}\text { Flow-rate-Nature of the water-Resin mass } \\
\text { flow-rate-Nature of the resin-Resin mass }\end{array}$ & $b_{124}$ & -8.8 \\
Nature of the water-Nature & $b_{134}$ & 3.8 \\
of the resin-Resin mass & $b_{234}$ & 10 \\
$\begin{array}{l}\text { Flow-rate-Nature of the water-Nature } \\
\text { of the resin-Resin mass }\end{array}$ & $b_{1234}$ & -8.8 \\
\hline
\end{tabular}

where $b_{0}$ is the average of the responses, $X_{i}$ the coded variable (value between -1 and +1 ) corresponding to the factor $i$, and $b_{i}$ the effect of the factor on the response $y$.

The effects were calculated from the average of the responses affected by the signs $(+)$ or $(-)$ corresponding respectively to the levels $(+1)$ and $(-1)$ of the factors.

Table II. Experimental matrix and responses corresponding to the study of the breakthrough volume of acetic acid by factorial design.

\begin{tabular}{|c|c|c|c|c|c|}
\hline Experiments & $\begin{array}{c}X_{1} \\
\text { flow-rate } \\
\left(m L \text { min }^{-1}\right)\end{array}$ & $\begin{array}{c}\quad X_{2} \\
\text { Nature of } \\
\text { the water }\end{array}$ & $\begin{array}{c}X_{3} \\
\text { Nature of } \\
\text { the resin }\end{array}$ & $\begin{array}{c}X_{4} \\
\text { Resin mass } \\
(g)\end{array}$ & $\begin{array}{c}\text { Response } \\
V_{p}(m L)\end{array}$ \\
\hline 1 & - & - & - & - & 350 \\
\hline 2 & + & - & - & - & 250 \\
\hline 3 & - & + & - & - & 100 \\
\hline 4 & + & + & - & - & 50 \\
\hline 5 & - & - & + & - & 350 \\
\hline 6 & + & - & + & - & 250 \\
\hline 7 & - & + & + & - & 30 \\
\hline 8 & + & + & + & - & 20 \\
\hline 9 & - & - & - & + & 900 \\
\hline 10 & + & - & - & + & 800 \\
\hline 11 & - & + & - & + & 200 \\
\hline 12 & + & + & - & + & 150 \\
\hline 13 & - & - & + & + & 700 \\
\hline 14 & + & - & + & + & 700 \\
\hline 15 & - & + & + & + & 80 \\
\hline 16 & + & + & + & + & 30 \\
\hline Level -1 & $3 \mathrm{~mL} \mathrm{~min}-1$ & MQ water & IRA-420 & $3 \mathrm{~g}$ & \\
\hline Level +1 & $9 \mathrm{~mL} \mathrm{~min}^{-1}$ & Tap water & IRA-910 & $7 \mathrm{~g}$ & \\
\hline
\end{tabular}




\section{Original articles}

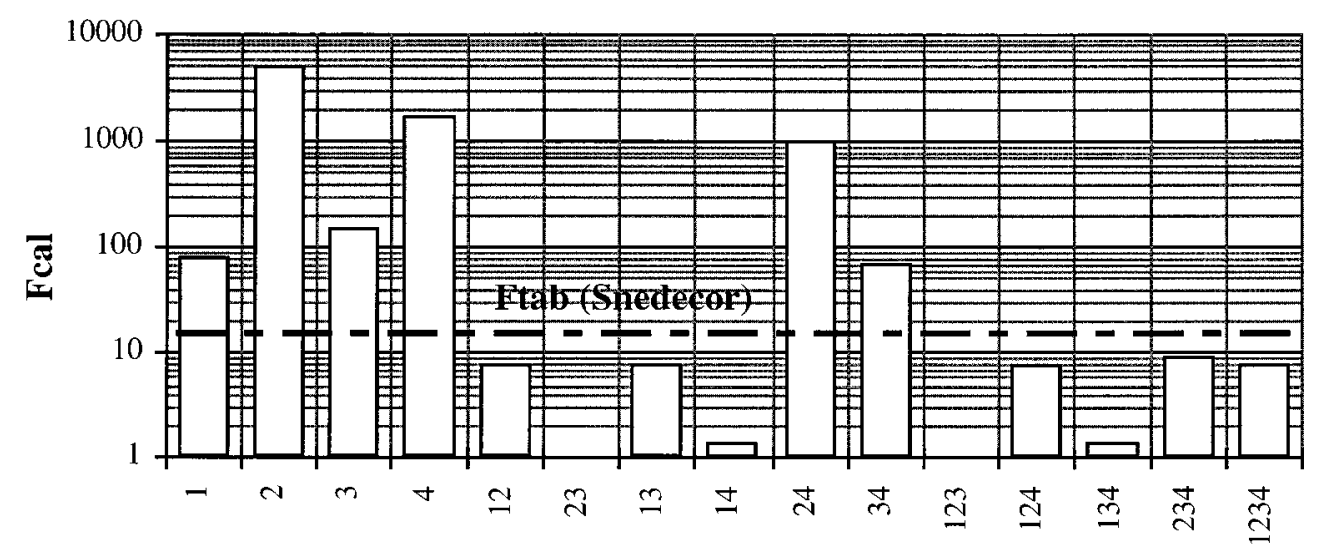

Factors-Interactions

Fig. 4. Signification of the studied factors and interactions.

The values of the coefficients (Tab. III) do not permit to evaluate directly the signification of the factors on the response. An analysis of the variance is therefore generally used. The basis hypothesis corresponds to the non-influence of a factor $i$. In this case, it can be demonstrated that the ratio $F_{\text {cal }}$ of the variances $V_{i}$ corresponding to the factor $i$, (relation (2)), and $V_{\mathrm{r}}$ to the residue $r$ (residual variance) (relation (3)), follows the Snedecor law (related to the comparison of two variances). The residual variance represents the variance due to a non-controlled factor or to a non-considered factor. It is a noise factor.

$$
V_{i}=\frac{S_{i}}{d d l_{i}}
$$

with $S_{i}=\frac{N}{n_{i}} \sum_{i} b_{i}^{2}, n_{i}$ the number of levels and $d d l_{i}=n_{i}-1$ the liberty degree.

$$
V_{\mathrm{r}}=\frac{S_{\mathrm{r}}}{d d l_{\mathrm{r}}}
$$

with $d d l_{\mathrm{r}}=(N-1)-\left(\sum_{i} d d l_{i}\right)$ and $S_{\mathrm{r}}=\sum_{i}\left(y_{i}-\bar{y}\right)^{2}-\sum_{i j} b_{i j}^{2}$

where $N$ is the number of experiments.

The total variance $V_{\mathrm{t}}$ is obtained from the sum of the factor variance $V_{i}$ and the non-explained variance, represented by the residue $V_{\mathrm{r}}$, expressed by the relation (4):

$$
V_{\mathrm{t}}=V_{i}+V_{\mathrm{r}^{\prime}}
$$

If the factor is influential (significant factor), the variance ratio:

$F_{\text {cal }}=\frac{V_{i}}{V_{\mathrm{r}}}$ is greater than the value given by the Snedecor tables, $F_{\text {tab }(\alpha, \beta)}$.

$F_{\text {tab }}$ is given, for a confidence interval of $95 \%$, by the Snedecor tables with considering the liberty degree $\alpha$ and $\beta$ related to the considered factor and to the residue [24].

In order to facilitate the calculation of the factor signification, two interactions can be neglected [24]. Up to second-order interactions are generally not significant. So, the 1-2-3 interaction, which has one of the lowest $b_{i, j, n}$, was

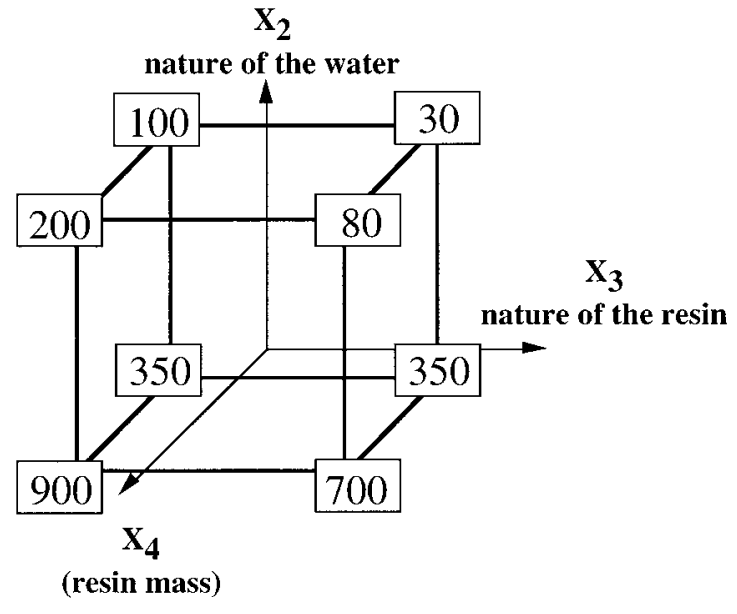

Fig. 5. 3D-representation of the experimental field and the corresponding responses (the flow-rate is fixed at $3 \mathrm{~mL} \mathrm{~min}^{-1}$ ).

neglected. The second-order interaction 2-3, which has the lowest effect, was also neglected for the variance calculation.

In these conditions: $F_{\text {tab } 1,2}=18.51$ and the residue is $0.02 \%$. This result confirms the non-influence of the neglected interactions in the variance calculation, and the appropriate choice of the studied factors [24].

The signification of the factors and their interactions is presented figure 4 .

All the studied factors and two interactions (2-4 and 3-4) are significant. These results confirm those described in table III, where the interactions related to the lowest $b_{i, j, n}$ coefficients are confirmed here to be not significant.

The percolation flow-rate is independent from the other factors. Consequently, it would be preferable to use a low flow-rate $\left(3 \mathrm{~mL} \mathrm{~min}{ }^{-1}\right.$ or less) in order to improve the acid retention, whatever the nature of the resin or the nature of the water. By keeping the flow-rate constant $\left(3 \mathrm{~mL} \mathrm{~min}{ }^{-1}\right)$, it is possible to represent in 3 dimensions the experimental field and the corresponding responses (Fig. 5).

The nature of the water and the resin mass are more influential than the flow-rate. However, their interaction can 
not be neglected, so these factors can not be considered independently. Indeed, it can be noted that the breakthrough volume increased with the resin mass together with the use of the MQ water. Consequently, the response decreased for the percolation of the tap water: $88 \%$ (for IRA-910) and $78 \%$ (for IRA-420) compared to the percolation of the MQ water. These results show the occurence of a matrix effect probably due to the presence of inorganic anions in tap water.

A difference of the breakthrough volume as a function of the nature of the resin can be also observed when the tap water is used. Better results were obtained with the IRA-420 resin (higher breakthrough volume). On the contrary, considering the experiments realized with MQ water, the breakthrough volume was approximately the same whatever the type of the resin. The adsorption of acetic acid would, hence, be the same for both resins. However, the small ions such as inorganic ions, diffuse more easily in macroporous resins (IRA-910) than in gel-type ones [16]. Therefore, in the case of the tap water percolation, inorganic anions may interfere more when the IRA-910 resin is used.

The experimental design has shown a matrix effect due, a priori, to inorganic anions. However, other interferents, such as organic compounds, may also reduce the retention of the acids. Indeed, they can be adsorbed on the resin by hydrophobic interactions with the polymeric phase.

So, a surface water sample was percolated through the IRA-420 resin in order to check the influence of interfering compounds on the retention of organic acids.

After the extraction of $500 \mathrm{~mL}$ of water, the inorganic anions were analysed by capillary electrophoresis and the organic compounds were evaluated by a TOC analyser.

Results are presented in table IV.

The electropherogram obtained for the analysis of the percolate presented a saturated peak corresponding to the chloride ions, which are the counter-ions of the quaternary ammonium groups of the resin. The other inorganic anions were adsorbed: their breakthrough volume was therefore higher than $500 \mathrm{~mL}$. The sum of their concentrations in meq $\mathrm{L}^{-1}$ corresponded to approximately the concentration of chloride ions exchanged.

Table IV shows that the DOC content of the sample (Rhône river water) is a little higher than the average generally observed for surface waters $\left(20 \mathrm{mg} \mathrm{L}^{-1}\right)[25,26]$. An important decrease of the DOC concentration was observed in the percolate. This shows a possible interference during the adsorption of the organic acids. However, only an anion-exchange mechanism was stated for acetic acid. So,

Table IV. Inorganic and DOC contents in the surface water sample and in the percolate of the IRA-420 resin (7 g).

\begin{tabular}{lccccc}
\hline & $\mathrm{SO}_{4}^{2-}$ & $\mathrm{NO}_{3}^{-}$ & $\mathrm{HCO}_{3}^{-}$ & $\mathrm{Cl}^{-}$ & $\mathrm{DOC}$ \\
\hline $\left.\begin{array}{l}\text { Sample }\left(\mathrm{mg} \mathrm{L}^{-1}\right) \\
\text { (meq L }\end{array}\right)$ & 50 & 1 to 5 & 50 & 15 & 32 \\
$\begin{array}{l}\text { Percolate }\left(\mathrm{mg} \mathrm{L}^{-1}\right) \\
\left(\mathrm{meq} \mathrm{L}^{-1}\right)\end{array}$ & 0 & 0 & 0 & 110 & 11 \\
\hline
\end{tabular}

only the inorganic anions would be responsible of the decrease of the breakthrough volume. However, the adsorbed DOC may contribute to diminish the retention of the acids for which hydrophobic interactions are involved (benzoic acid, 2,4-D...).

\section{Conclusion}

Before their chromatographic analysis, the organic acid micropollutants present in water samples should be extracted and preconcentrated in order to reach the level imposed by the regulation. The anion-exchange extraction seems therefore to be particularly well adapted because of its specificity.

In order to applied this procedure, several parameters able to influence the acid retention were studied. They were the mass and the nature of the resin, the percolation flow-rate and the matrix of the water sample. The possible influence of the interactions was also taken into account and a $2^{4}$ factorial design was performed. It was concluded that a high flow-rate affected the compound adsorption, whatever the level of the other factors. The influence of the sample matrix was also important, and was attributed to the competition between inorganic anions and organic acids. The significant interaction "sample matrix - nature of the resin" shown that the matrix influence is related to the nature of the anionexchange sorbent. A larger sample volume (up to $200 \mathrm{~mL}$ ) can be percolated through a gel-type resin (IRA-420) where the inorganic interferents diffused more slowly than in a macroporous resin (IRA-910).

It was also stated that some other non-ionic interferents can be adsorbed on the polymeric sorbent and can affect the retention of the most hydrophobic acids. Consequently, the anion-exchange extraction may not allow to reach a sufficient concentration factor in the aim of trace analysis. In this case, a supplementary purification step should be envisaged.

\section{References}

1. Thurman, E. M. Organic geochemistry of natural waters, Martinus Nijhoff/Dr W. Junk Publishers, Dordrecht, 1985.

2. Doré, M. Chimie des oxydants - Traitement des eaux, Tech. \& Doc. Lavoisier, Paris, 1989.

3. Legube, B. Analusis 1991, 19, il5-il6.

4. Martin, B. La matière organique des eaux de surface: fractionnement, caractérisation et réactivité, Thèse de doctorat en science, Université de Poitiers, 1995.

5. Ben Amor, H.; De Laat, J.; Doré, M. Env. Tech. Lett. 1988, 1105-1114.

6. Singer, P. C. J. Env. Eng. 1994, 120, 727-744.

7. US Environmental Protection Agency, Guidelines establishing test procedures for the analysis of pollutants under the clean water act, Method 8150, Chlorinated herbicides, 1986, revision 0 .

8. Mc Grath, L. T.; Weir, C. D.; Maynard, S.; Rowlands, B. Anal. Biochem. 1992, 207, 227-230.

9. Tanaka, M.; Yasaka, Y.; Wu, H. L.; Shono, T. Fresenius Anal. Chem. 1990, 336, 515-516.

10. Fogelqvist, E.; Joseffson, B.; Roos, C. J. HRCC \& CC 1980, 3, 568-574.

11. Font, G.; Manes, J.; Molto, J. C.; Pico, Y. J. Chromatogr. 1993, 642, 135-161.

12. Aiken, G. R.; Mc Knight, D. M.; Thorn, K. A.; Thurman, E. M. Org. Geochem. 1992, 18, 567-573. 


\section{Original articles}

13. Hodgeson, J.; Collins, J.; Bashe, W. J. Chromatogr. 1994, 659, 395-401.

14. Di Corcia, A.; Marchetti, M. Anal. Chem. 1989, 61, 13631367.

15. Federici-Coquart, F. Préconcentration et analyse en ligne des micropolluants organiques dans les eaux par chromatographie en phase liquide - Étude chromatographique du carbone poreux, Thèse de doctorat en science, Université Paris 6, 1993.

16. Tremillon B. Les séparations par les résines échangeuses d'ions, Gauthier-Villars, Eds. Paris, 1965.

17. Poole, C. F.; Zlatkis, A. Anal. Chem. 1980, 52, 1002-1016.

18. Richard, J. J.; Chriswell, C. D.; Fritz, J. S. J. Chromatogr. 1980, 199, 143-148.

19. Junk, G. A.; Richard, J. J.; Grieser, M. D.; Witiak, D.; Witiak, J. L.; Arguello, M. D.; Vick, R.; Svec, H. J.; Fritz, J. S.; Calder, G. V. J. Chromatogr. 1974, 99, 745-762.
20. Yamada, E.; Tagushi, H.; Karatani, H.; Sato, M. Anal. Sci. 1995, 11, 67-72.

21. Zhu, A.; Xu, G. Y. J. Chromatogr. 1984, 314, 421-428.

22. Majors, R. E. $L C-G C$ 1984, 4(10), 972-984.

23. Rekker, R. F.; Mannhold, R. The hydrophobic fragmental approach - Calculation of drug lipophilicity, VCH Eds., Weinheim, New-York, Basel, Cambridge, 1992.

24. Sado, G.; Sado, M. C. Les plans d'expérience: de l'expérimentation à l'assurance qualité, Afnor Technique Eds., Paris, 1991.

25. Crathorne, B.; Fielding, M.; Steel, C. P.; Watts, C. D. Environ. Sci. Technol. 1984, 18, 797-802.

26. Subra, P.; Hennion, M. C.; Rosset, R. Analusis 1988, 16, $1-22$. 